The INL is a

U.S. Department of Energy

National Laboratory

operated by

Battelle Energy Alliance

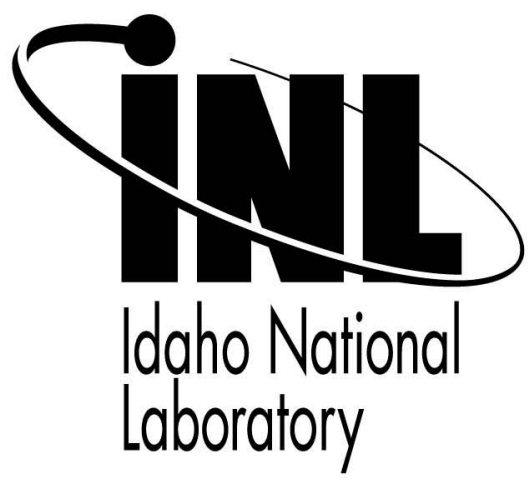

\section{Installation and Final Testing of an \\ On-Line, Multi-Spectrometer}

Fission Product Monitoring System

(FPMS) to Support Advanced Gas

Reactor (AGR) Fuel Testing and

Qualification in the Advanced Test

Reactor

\section{IEEE Nuclear Science Symposium}

John K. Hartwell

Dawn M. Scates

Mark W. Drigert

John B. Walter

\section{October 2006}

This is a preprint of a paper intended for publication in a journal or proceedings. Since changes may be made before publication, this preprint should not be cited or reproduced without permission of the author. This document was prepared as an account of work sponsored by an agency of the United States Government. Neither the United States Government nor any agency thereof, or any of their employees, makes any warranty, expressed or implied, or assumes any legal liability or responsibility for any third party's use, or the results of such use, of any information, apparatus, product or process disclosed in this report, or represents that its use by such third party would not infringe privately owned rights. The views expressed in this paper are not necessarily those of the United States Government or the sponsoring agency. 


\title{
Installation and Final Testing of an On-Line, Multi- Spectrometer Fission Product Monitoring System (FPMS) to Support Advanced Gas Reactor (AGR) Fuel Testing and Qualification in the Advanced Test Reactor
}

\author{
John K. Hartwell, Member, IEEE, Dawn M. Scates, Mark W. Drigert, and John B. Walter
}

\begin{abstract}
The US Department of Energy (DOE) is initiating tests of reactor fuel for use in an Advanced Gas Reactor (AGR). The AGR will use helium coolant, a low-power-density graphitemoderated core, and coated-particle fuel. A series of eight (8) fuel irradiation tests are planned for the Idaho National Laboratory's (INL's) Advanced Test Reactor (ATR). One important measure of fuel performance in these tests is quantification of the fission gas releases over the nominal 2-year duration of each irradiation experiment. This test objective will be met using the AGR Fission Product Monitoring System (FPMS) which includes seven (7) online detection stations viewing each of the six test capsule effluent lines (plus one spare). Each station incorporates both a heavilyshielded high-purity germanium (HPGe) gamma-ray spectrometer for quantification of the isotopic releases, and a $\mathrm{NaI}(\mathrm{TI})$ scintillation detector to monitor the total count rate and identify the timing of the releases. The AGR-1 experiment will begin irradiation in December 2006. To support this experiment, the FPMS has been completely assembled, tested, and calibrated in a laboratory at the INL, and then reassembled in its final location in the ATR reactor basement. This paper presents the details of the equipment performance, the control and acquisition software, the installation in the ATR basement, and the test monitoring plan.
\end{abstract}

\section{INTRODUCTION}

The US Department of Energy (DOE) is embarking on a series of tests of coated-particle reactor fuel designed for use in an Advanced Gas Reactor (AGR). The AGR is based on high-temperature gas-cooled reactor (HTGR) technology. The primary distinguishing features of HTGRs are the use of helium coolant, a low-power-density graphite-moderated core

Manuscript received October 30, 2006. Prepared for the US Department of Energy, Assistant Secretary for Nuclear Energy, under DOE Idaho Operations Office Contract DE-AC07-99ID13727.

All authors are with the Idaho National Laboratory, PO Box 1625, Idaho Falls, ID 83415-2114. Contact information follows:

John K. Hartwell (208-526-9366, email john.hartwell@inl.gov)

Dawn M. Scates (208-526-5503, e-mail dawn.scates@inl.gov)

Mark W. Drigert (208-526-1057, e-mail mark.drigert@inl.gov)

John B. Walter (208-526-0033, e-mail john.walter@inl.gov) capable of withstanding very high temperatures, and coatedparticle fuel. As one part of this fuel development program a series of eight (8) fuel irradiation tests are planned for the Idaho National Laboratory's (INL's) Advanced Test Reactor (ATR) [1]. These experiments are what are termed "Instrumented Lead Experiments" in that a lead attached to the in-pile test train conveys instrument wires and gas tubes to the outside of the reactor vessel [2]. One important measure of the fuel performance in these tests is quantification of the fission gas releases over the duration of each irradiation experiment.

Most of the planned fuel test experiments will incorporate a multi-capsule fuel test train inserted into an irradiation position in the ATR. In the first experiment (AGR1), the test trains incorporates six (6) individual test capsules. Each capsules contains about 51,000 TRISO (TRIstructural ISOtopic) coated uranium oxicarbide fuel particles supported in a graphite matrix. Each capsule will be continuously swept with an inert gas during irradiation. The effluent gas from each of the six capsules must be independently monitored in near real time and the activity of various fission gas nuclides determined and reported. To meet this important test objective the FPMS design includes seven (7) detection stations, which allows for one spare. Each station incorporates both a heavilyshielded high-purity germanium (HPGe) gamma-ray spectrometer for identification and quantification of the isotopic releases, and a sodium iodide $[\mathrm{NaI}(\mathrm{Tl})]$ scintillation detector to monitor the total gamma-ray count rate and identify the timing of the releases. The gamma-ray spectrometer detectors are closed-end coaxial hyperpure germanium (HPGe) detectors with a nominal relative efficiency of $10 \%$. The gross gamma-ray radiation monitor detectors are $\varnothing 25 \mathrm{~mm} \mathrm{X} 25 \mathrm{~mm} \mathrm{NaI(Tl)} \mathrm{detectors.} \mathrm{Design}$ and expected performance parameters for this unique system, termed the AGR Fission Product Monitoring System (FPMS), have been reported [3]. 
The AGR-1 experiment was ready to insert into the ATR on September 27, 2006, and will begin irradiation at the start of an ATR operation cycle tentatively scheduled for December 2006. The test irradiation is scheduled for about a 2 year duration, during which the FPMS will acquire near real time data on fission gas releases.

The FPMS has been completely assembled, tested, and calibrated in a laboratory at the INL, and then moved and reassembled in its final location in the ATR reactor basement. This paper presents the details of the equipment performance, the control and acquisition software, the installation in the ATR basement, and the test plan for the experiment monitoring.

\section{THE AGR-1 EXPERIMENT}

The AGR-1 "test train" (the in-reactor portion of the experiment) incorporates 6 individual test capsules. Each capsule contains 12 fuel "compacts" arranged in three stacks of four compacts per stack supported in a graphite matrix. Each compact contains about 4300 TRISO-coated fuel particles, thus each capsule contains about 51,000 fuel particles. Each individual capsule will be continuously swept with an inert sweep gas during irradiation. The FPMS continuously monitors the sweep gas effluent from each capsule to provide fuel integrity data.

The FPMS is required to monitor the fuel performance by sensing and quantifying the increased fission gas activity in the sweep gas if a particle failures (meaning the rupture of a particle's TRISO coating). This activity increase must be sensed over a continuous fission gas release from any "tramp" uranium contamination of the fuel particles or compacts, and from a small number of initially defective fuel particles. FPMS response modeling indicates that the system will easily meet this design goal [3].

\section{THE FISSION PRODUCT MONITORING SYSTEM}

\section{A. Sample routing and FPMS installation}

Figure 1 presents a simplified diagram of the AGR-1 gas flow and fission product monitoring system. The sweep gas (which for temperature control can be either helium, neon, ${ }^{3} \mathrm{He}$, or mixtures thereof) flows to each individual fuel capsule. Each capsule effluent line (there are six) exits the reactor vessel through an experiment flange, routes the gas through a particulate filter (primarily for protection against irradiated particles downstream), and then enters into a shielded "cubicle" in the ATR basement. The effluent lines are contained in a shielded pipe chase channel as they run along the cubicle wall until they reach the location of their associated monitoring station. Each sample line then leaves the pipe chase channel, passes through the associated gross activity monitor, and then into the HPGe spectrometer shield where it flows through a $50 \mathrm{~cm}^{3}$ sample chamber enclosed in a beaker located at the center bottom of each shield. Fission gas transport

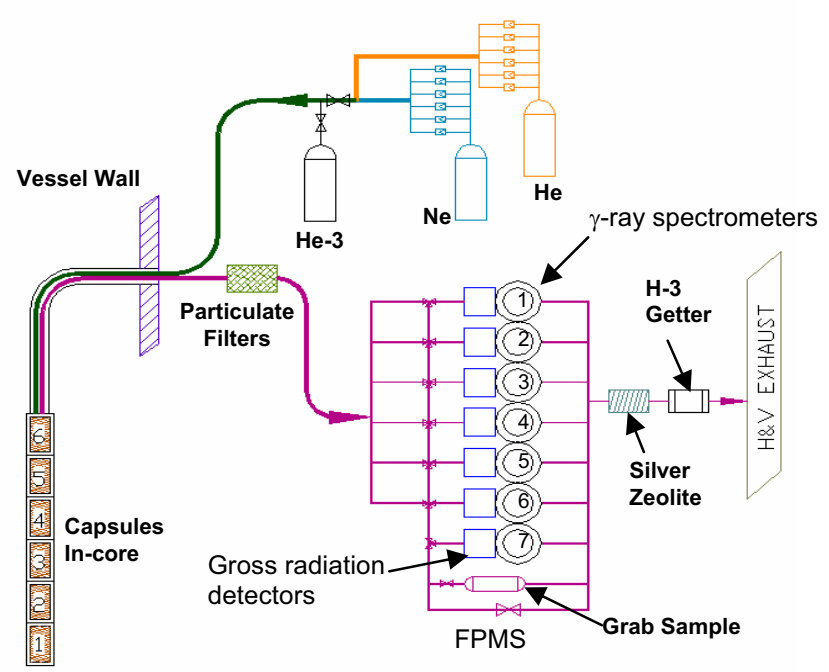

Fig. 1. A simplified diagram of the AGR-1 sweep gas flow and fission product monitoring system.

from capsule to spectrometer are expected to be on the order of 100 to 300 seconds. The sample chamber is viewed by the HPGe detector from below through a collimator. Collimators with circular aperture diameters of $38.1 \mathrm{~mm}, 19.0 \mathrm{~mm}$, and 9.5 $\mathrm{mm}$ are available.

Figure 2 is a photograph of the AGR-1 FPMS installation in the ATR. Figure 3 is an annotated photo of a single station. Figure 4 shows the details of the FPMS spectrometer collimator, and flow-through sample chamber.

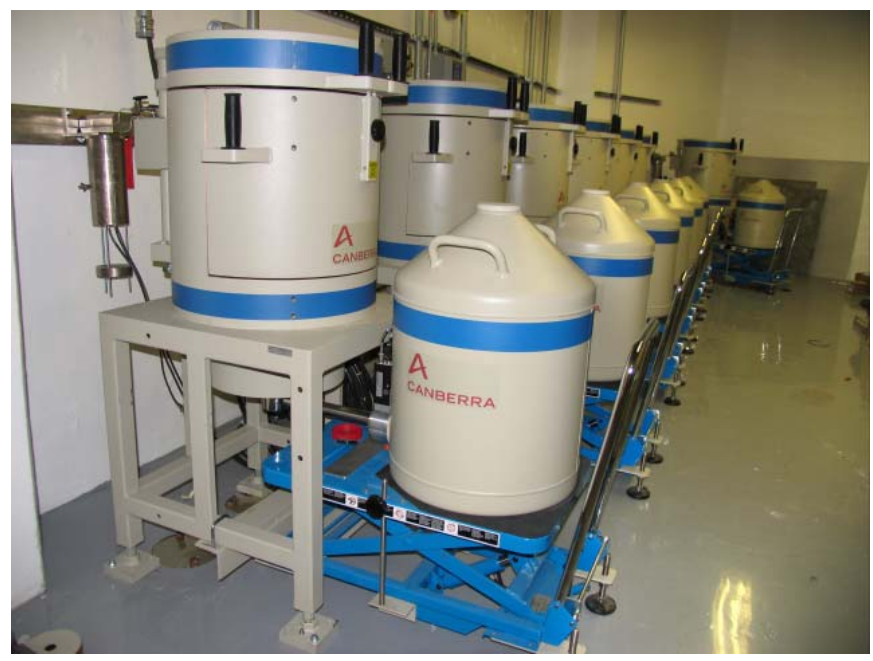

Fig. 2 A photograph of the seven FPMS stations installed in the ATR basement. 


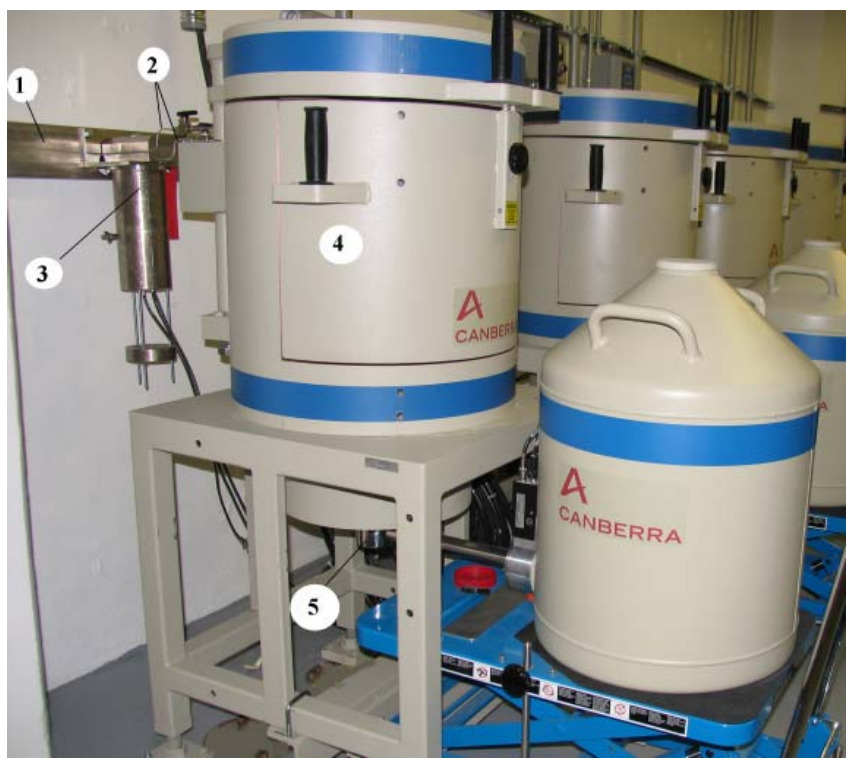

Fig. 3 An annotated photo of an FPMS monitoring station. The pipe chase channel (1) installed on the wall carries the test capsule effluent lines to and from the monitoring stations. Each capsule effluent line (2) branches from the channel, passes through the gross radiation monitoring station (3) where it is viewed by a shielded up-looking $\mathrm{NaI}(\mathrm{Tl})$ detector, and then into the HPGe spectrometer shield (4) and through the spectrometer sample chamber viewed from the bottom by the HPGe detector (5). From the chamber the effluent line returns to the pipe chase channel and leaves the cubicle to of treatment filters and then to the plant ventilation system.

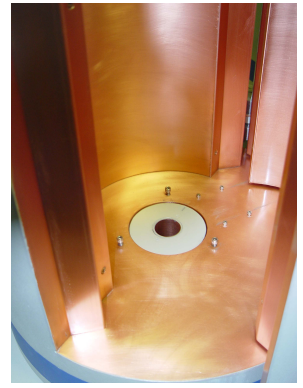

(1)

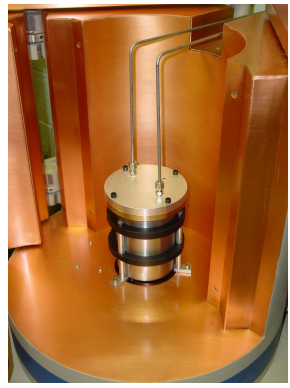

(2)

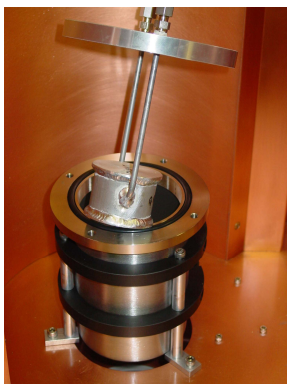

(3)
Fig. 4 Depicted from left to right are: (1) a collimator installed in the floor of an FPMS shield (The detector is up-looking with the detector face located 127 $\mathrm{mm}$ below the inner floor of the shield.); (2) The sample assembly fully assembled and positioned over the collimator aperture; and (3) The actual flow-through sample chamber removed from the containment beaker. Note the effluent gas lines that connect to lines from the pipe chase channel.

The FPMS electronics and control computer are housed in a set of air-conditioned racks located in an access area outside of the installation cubicle. As described previously [3], each spectrometer is provided with a NIM amplifier and ADC with histogramming memory implemented in Canberra Acquisition Interface Modules (AIMs). The spectrometer systems implement the INL technology of pulse injection with subsequent removal that we find to be essential for unattended systems [4].

A set of seven $\mathrm{NaI}(\mathrm{Tl})$ detector-based "gross monitor" systems (one for each FPMS station) will record the total gamma radiation from sources in the effluent line, providing better release event timing and identification than the spectrometer results. Each gross monitor consists of a $25-\mathrm{mm}$ diameter by $25-\mathrm{mm}$ long $\mathrm{NaI}(\mathrm{Tl})$ detector with integral PMT, voltage divider and preamplifier viewing a $25-\mathrm{mm}$ long segment of the associated effluent line. Each gross monitor detector is shielded to protect from ambient background, and collimated to view the appropriate line segment. The gross detectors are initially installed with their front face about 3 $\mathrm{mm}$ from the wall of the capsule effluent line, but are mounted so that they can be moved back from the viewed section of the effluent line in order to keep them within their linear count rate range. The $\mathrm{NaI}(\mathrm{Tl})$ detector output pulses are amplified and then provided to the input of a discriminator-equipped multichannel scaler module (MCS.) (The system uses Canberra Multiport IIs as the multichannel scalers.)

\section{B. Communications and Control}

The data acquisition modules (AIMs and Multiport IIs) communicate with the control computer via a private Ethernet subnet. The control computer is high-end personal computer with dual $3.2 \mathrm{GHz} 64$ bit (XENON) processors running the Windows XP operating system. The control computer also communicates with the laboratory's intranet through a separate Ethernet interface, enabling remote control and data access.

Acquisition control and data archival and analysis software have been developed to automate the acquisition tasks. The control software is designed to operate without continual operator intervention. The communications between the control program and the Canberra acquisition modules are carried out through a proprietary Canberra Virtual Data Manager (VDM). The VDM handles all of the low-level communications between the commands sent out by the control program and the MCA/MCS hardware. The control program communicates with the VDM using the proprietary Canberra Genie 2000 Programming Library.

The control program is designed to monitor the operations of each of the seven instrumented monitoring stations continually. The operation of each station is logged to a disk file and will provide a permanent record of the operation of the system over the course of the fuel irradiation. The user interacts with the control system through a graphical user interface to select which channels in the measurement system to use and what type of measurement to conduct on each system. The measurement parameters for each measurement system can be set independently.

The control software monitors the operation of the data acquisition and at the end of the preset measurement time, saves the collected spectra to disk and initiates the online analysis task. Acquired spectra are analyzed automatically using the INL-developed PCGAP gamma-ray spectral analysis code [5] [6]. At the completion of the online analysis the control system restarts the data collection phase automatically. Additionally, the control software performs incremental saves during each acquisition. These incremental saves are "snapshots" of the acquired data at intervals preset by the operator. The incremental data protect against equipment 
failures or electronic upsets during each acquisition. Operators will periodically review the acquired FPMS data and can choose to retain or purge the incrementally saved data.

The control software has been written to continue the measurement/analysis cycle until stopped by the operator. Any errors encountered are recorded in the appropriate log file. To facilitate the recovery from failure of the control system software or the computer system the control program checks the most recently saved status information of the measurement stations. If one or more of the measurement stations were active when the control program last terminated the system will automatically continue the previous measurement. The AIM and Multiport II hardware will continue active collection even if the connection to the VDM is lost as long as power to the AIM and Multiport II hardware is not interrupted.

The operation of the control software is monitored by a separate process. This process will restart the control system software if it should become non-responsive for any reason. The monitoring process periodically reports the status of the control system and any problems requiring a restart of the control program to designated users via electronic mail. A failure in the computer hosting the control software will be reported to an operator by means of an alarm activated by a network-controllable power switch attached to the host computers private Ethernet subnet. The switch is monitoring a CPU "heartbeat." If the heartbeat stops, the alarm activates.

\section{Calibration and Testing}

The FPMS units were fully assembled in our laboratory and tested. The control software was extensively tested for longterm stability and error recovery.

The $\mathrm{NaI}(\mathrm{Tl})$ radiation gross detectors were tested to determine the indicated rate above which the units deviated from linear by more than about $10 \%$. This was determined to be at an indicated rate of $20 \mathrm{kc} / \mathrm{s}$. The gross detectors will be repositioned relative to the effluent gas lines in order to maintain a counting rate below $20 \mathrm{kc} / \mathrm{s}$.

The FPMS spectrometers were also tested to document their performance. In addition to measurements that included photopeak resolution and relative efficiency to confirm that the detectors conformed to their purchase specifications, we tested the performance of the configured spectrometers at elevated input rates. Using a set of ${ }^{152} \mathrm{Eu}$ sources of precisely know relative activities and experimental techniques that have been previously reported [7] [8], we measured the energy stability, peak shape parameters, and the quantitative rate effects correction accuracy of one of the configured spectrometers (G4) as the total input counting rate increased from about $500 \mathrm{c} / \mathrm{s}(0.5 \%$ dead time) to more than $200,000 \mathrm{c} / \mathrm{s}$ (about $80 \%$ dead time). While the peak shape performance was adequate, the impressive results were the energy stability and the quantitative accuracy of the activity measurements. Primarily due to the use of the pulse injection system [4] for energy calibration and rate effects corrections, the calculated energy of the $1408 \mathrm{keV}$ line never deviated more than 0.23 $\mathrm{keV}$ from the correct value even though the $1408 \mathrm{kev}$ peak centroid dropped almost 3 channels at the highest rate; and, the quantitative activity reported was always within the measurement uncertainty of the standard value. Figure 5 presents the percentage recovery of the activity value computed from the $1408 \mathrm{keV}$ line as a function of the input counting rate.

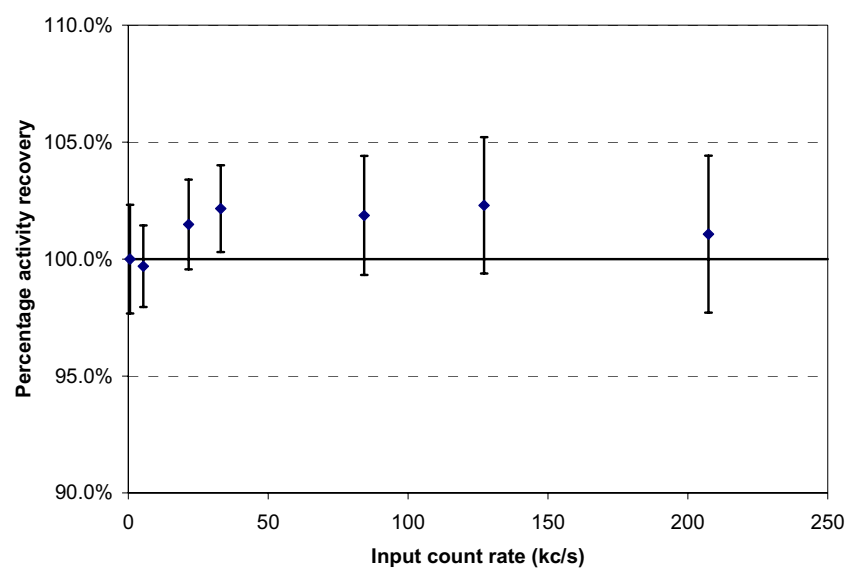

Fig. 5 Quantitative performance of the AGR G4 spectrometer as a function of input counting rate as calculated from the $1408 \mathrm{keV}$ line of ${ }^{152} \mathrm{Eu}$. Uncertainty limits are one estimated standard deviation.

Each spectrometer and collimator combination was calibrated for photopeak efficiency using a set of standards prepared specifically for this task. A set of three of the $50 \mathrm{~cm}^{3}$ sample chambers specially manufactured to incorporate a removable top, were fabricated in an INL machine shop, and shipped to a radioactive standards vendor. The vendor filled these chambers with a "simulated gas standard" consisting of a mixture of low density $(\sim 0.2 \mathrm{~g} / \mathrm{cm} 3)$ polymer and the chosen radioactive sources. This low density source requires no attenuation correction for gamma-rays above $59 \mathrm{keV}$ [9] and homogenously fills the sample volume. Vendor-calibrated and NIST-traceable standards included a mixed radionuclide source (MRS) providing calibration lines from $59.5 \mathrm{keV}$ to $1836 \mathrm{keV}$, and a standard of ${ }^{152} \mathrm{Eu}$ providing additional calibration lines from $121.8 \mathrm{keV}$ to $1408 \mathrm{keV}$. The third chamber was prepared with the same low density matrix, and a less well known amount of a source that we provided of ${ }^{232} \mathrm{U}$ in equilibrium with its ${ }^{228} \mathrm{Th}$ daughter and progeny. This source provides useful lines from $238.6 \mathrm{keV}$ to $2614.5 \mathrm{keV}$. This source was calibrated for use as a standard by a "bootstrap" approach using the calibrated MRS and ${ }^{152} \mathrm{Eu}$ sources to develop a photopeak efficiency curve from $59 \mathrm{keV}$ to $1836 \mathrm{keV}$. Spectra taken in an identical geometry on the low density ${ }^{232} \mathrm{U}+$ daughters source were then carefully analyzed using the $238.6,300.1,583.2,727.3,860.6$, and $1620.7 \mathrm{keV}$ lines that were within the NIST-traceable efficiency curve range to determine the ${ }^{232} \mathrm{U}+$ daughter activity. This procedure provided a standard value with an estimated total relative uncertainty $(\mathrm{k}=2)$ of $\pm 5 \%$. Using this 
derived activity value, the FPMS efficiency curves were measured to $2614.5 \mathrm{keV}$ and extrapolated a short distance to $3000 \mathrm{keV}$. The efficiency curves were fit and tabular data derived using the EFFICIENCY program of the PCGAP suite [5]. When the operator specifies the collimator in place for a given acquisition, the proper efficiency curve is automatically selected for the on-line spectral analyses.

\section{AGR-1 TEST MONITORING PlanS}

The AGR-1 test experiment is presently scheduled to start in December of 2006 and have a duration of slightly more than 2 years. The irradiation will be in segments that conform to the ATR operating schedule. The ATR normal operational cycle consists of an irradiation run of nominally 40 to 50 days, followed by a shutdown (outage) of a nominal 7 to 14 days [2].

The AGR-1 experiment capsules will be swept with the inert gas mix during reactor operation. During these reactor runs the FPMS will operate in a continual loop of data acquisition, archival, and analysis. The dwell time per channel of the Multiport II MCSs will be coordinated with the spectrometer acquisition real time to simplify post test processing and data correlation. Initial acquisition times (determined through real time presets) will be 10000 seconds, with adjustments as the effluent gas activity changes during the irradiation. The 10000 second acquisition times allow sufficient sensitivity to potential particle releases [3] while providing more than the required minimum of an activity measurement each 24 hours.

When the ATR shuts down for an outage the sweep gas flow will be continued, and the FPMS will continue to monitor capsule effluent fission gas activities for up to 48 hours. These data may, through decay progeny [like ${ }^{135 \mathrm{~m}} \mathrm{Xe}$ (15.3 min.),] elucidate the integral release of reactive radioiodines [like $\left.{ }^{135} \mathrm{I}(6.6 \mathrm{hr})\right]$. After this extended monitoring period, the remainder of each outage will be used for maintenance, performance checks, QA checks, and pulser energy equivalent calibrations.

The FPMS control computer is connected to the INL intranet. Approved users can use the remote desktop feature of Windows XP to monitor the operation of the control program, and access spectra and results. A user interface and display routine allows users to review plots of computed radionuclide activities as a function of time over the duration of the experiment. All FPMS computer files will be automatically archived to a network server using the laboratory's archive and backup storage manager. Full backups will be automatically performed weekly with incremental backups of any new or changed files daily.

\section{CONCLUSiOn}

The AGR FPMS has been designed, tested, and installed in its location in the Advanced Test Reactor. This system will quantify the radioactive fission gas content of effluent gasses during testing of AGR fuel. The first test in this series, AGR-
1 , is presently scheduled to start irradiation in December 2006.

\section{REFERENCES}

[1] Advanced Gas Reactor Team, M. A. Feltus, Program Manager, D. A. Petti, R. R. Hobbins, J. M. Kendall, and J. J. Saurwein, Editors, "Technical program plan for the Advanced Gas Reactor fuel development and qualification program," Idaho National Laboratory, Idaho Falls, ID, Tech. Rep. INL/EXT-05-00465 Revision 1, Aug. 2005.

[2] Idaho National Engineering and Environmental Laboratory, "Users handbook for the Advanced Test Reactor," INEEL Laboratory Report INEEL/EXT-02-01064, Sept. 2002.

[3] J. K. Hartwell, D. M. Scates, and M. W. Drigert, "Design of an on-line, multi-spectrometer fission product monitoring system (FPMS) to support Advanced Gas Reactor (AGR) fuel testing and qualification in the Advanced Test Reactor," 2005 IEEE Nuclear Science Symposium Conference Record, Paper N30-4, October 2005, Puerto Rico. To be published in IEEE Trans. Nucl. Sci.

[4] J. K. Hartwell and S. G. Goodwin, "Pulse injection with subsequent removal: Implementation and applications," IEEE Trans. Nucl. Sci., vol. 36, no. , pp. 801-805, Feb. 1989. See also US Patent \#4,968,889 (1990).

[5] E. W. Killian and L. V. East, "PCGAP: Application to analyze gammaray pulse-height spectra on a personal computer under Window $\mathrm{NT}^{\mathfrak{O}}$," J. Radioanalytical Nucl. Chem., Vol 233, No. 1-2, pp. 109-114, 1998.

[6] E. W. Killian and J. K. Hartwell "PCGAP: Users guide and algorithm description," Idaho National Engineering and Environmental Laboratory Report INEEL/EXT-2000-00908, Sept. 2000.

[7] J. K. Hartwell and G. D. McLaughlin, "A comparison of the high countrate performance of two commercially-available digital gamma-ray spectrometers," Radioact. Radiochem., vol. 11, no 4, pp. 5-12, 2000.

[8] D. M. Scates and J. K. Hartwell, "A comparison of the high count-rate performance of three commercially available digital signal processors," Appl. Radiat. Isot., vol 63, pp.465-473, 2005.

[9] “Simulated Gas Standards," http://www.analyticsinc.com/prod02.htm. 